\title{
Valuable, but not maximal: it's time behavior therapy attend to its behaviorism
}

\author{
Arthur W. Staats ${ }^{1}$ \\ Department of Psychology, University of Hawaii, Honolulu, HI 96822, Hawaii
}

Received 12 March 1998

\begin{abstract}
The field of behavior therapy is not in touch with itself in terms of its overarching behaviorism. Many erroneously consider its basic behaviorism to have been radical behaviorism and continue to look to develop behavior therapy (including behavior analysis and behavioral assessment) within that framework. But that approach turns out to be much less than maximal because there is a more advanced, better developed behaviorism within which to conduct and project the field. There is much that behavior therapy is not doing in practice and research because it is not making full use of that behaviorism foundation. (C) 1999 Elsevier Science Ltd. All rights reserved.
\end{abstract}

\section{Introduction}

Rosemery Nelson-Gray has been an outstanding behavior therapist for a long time. She and Richard Farmer have done highly productive works in the past, and the present paper (NelsonGray \& Farmer, 1998) adds to that list with its valuable contributions to the analysis of personality disorder (PD) and its assessment and treatment. But the paper is also an exemplar: it exemplifies a general methodology, for one thing, in attempting to combine behavioral materials with those from traditional psychology. I have called this behaviorizing psychology and believe that it is essential for the progress of behavior therapy (behavior modification, applied behavior analysis, and behavior assessment) and for behaviorism more generally. But, while behaviorizing psychology is a very essential theory-construction agenda, an advancement past standard radical behaviorism, it can be approached (or avoided) in different ways that are critical. In this commentary I am going to address what the Nelson-Gray and Farmer paper

\footnotetext{
${ }^{1}$ Fax: (808) 377-3084. 
represents as a general approach or model. I will accept the value of the various specifics of their important contribution as self-evident to behavior therapists.

\section{There are several behaviorisms, with commonality as well as basic differences}

Iverson (1994) and Franks (1998) have identified five behaviorisms as important conceptual frameworks in behavior therapy: radical behaviorism (RB), cognitive-social behaviorism, and paradigmatic (or psychological) behaviorism (PB), as well as methodological behaviorism and neobehaviorism. Let me suggest that only the first three maintain a continuing development that is generally relevant to behavior therapy. Those three, as do all behaviorisms, share much commonality. For example, the three accept the facts of conditioning, and almost of the works of behavior therapy that involve reinforcement or classical conditioning derive from these three behaviorisms. Nevertheless, there are fundamental differences, in the theories of the basic principles, in the methodology of theory construction, in the breadth of studies produced and organised within the behaviorisms, in the problems treated, in the directions for advancement projected, in the question of relating to psychology, and such.

Relevant here is the fact that the Nelson-Gray and Farmer (1998) "functional analytic" approach, while more generally influenced, also anchors itself in the radical behaviorism tradition, which brings along characteristics of that tradition, Nelson-Gray and Farmer deal with a very important topic, they take valuable positions and make valuable analyses. But I will argue that their functional analytic approach, by being harnessed with characteristics of radical behaviorism, does not maximise what behaviorism has to offer to such endeavors. In developing this view I will suggest that a better approach for behavior therapists is to use a different one of the five behaviorisms - psychological behaviorism.

\section{Informing functional analysis with abnormal psychology}

A major argument of the Nelson-Gray and Farmer article (1998), consuming the first three pages, aims to justify the use of an abnormal psychology (DSM-IV) definition of the behavior disorders. However, that justification is only necessary because the radical behaviorism position "eschew[s] the concepts of personality and personality disorder (PD) because of their trait and mental illness connotations and because of the inferential [mentalistic] nature of such constructs" (Nelson-Gray and Farmer, 1998, p. 3). It is because radical behaviorism has not provided a conceptual bridge to personality and the knowledge products of abnormal psychology that makes the justification necessary. Not only is the conceptual bridge absent, but radical behaviorism is still mired in the simplistic anti-mentalism of Watson and Skinner and engaged in battling the intervening variable strategies of Tolman and Hull (see Hayes \& Brownstein, 1986). So the approach has never developed concepts of personality and abnormal personality that allow it to connect to the work of non-behavioral psychology, including the DSM materials. Without having a behaviorism that resolves the separation between behaviorism and personality concepts, Nelson-Gray and Farmer are forced to just assert that 
their functional analysis position and traditional abnormal psychology definitions can "inform" one another. This is but the same type of eclecticism that has been followed by cognitive behaviorists - better than radical behaviorism rejection of psychology, but less powerful than unified, principled theory. Let me suggest that the radical behaviorism foundation used by many behavior therapists forces them to be eclectic; because their basic approach does not provide the foundation for unifying with traditional psychology materials in a "principled" way.

Let me contrast this eclecticism to psychological behaviorism, which began with a program of providing behavioral analyses of traditional psychology concerns, including emotion, selfconcept, intelligence, and cognition. This was done behaviorally, based on specific research, and it has dealt with many topics, in each case yielding a basis for unification. As one example, progressively a behavioral definition of personality arose as composed of basic behavioral reportoires (BBRs), learned as dependent variables. But, once learned, the BBRs, help determine what the individual will experience and learn, and how the individual will behave. That makes them independent variables, satisfying the "personality causation" concern of traditional psychology that behaviorism has rejected (Staats, 1963, 1975, 1996).

When a behavior therapist sets about making a behavioral analysis of some type of abnormal behavior problem in which there are already works by traditional psychologistsand that is a very general case - it is much more advantageous to employ a behaviorism that has already worked out the means for making such unified analyses, rather than one that emphasizes the rejection of psychology and that has no or poorly developed tools for the task.

\section{The SORC model and personality and personality disorders}

Nelson-Gray and Farmer employ Goldfried and Sprafkin's (1976) SORC model which states that behavior, including abnormal behavior, is a function of the environment, the organism, and the consequences of the behavior. The model may be considered an advancement over radical behaviorism's lack of consideration of the organism in the analysis of behavior. But the $\mathrm{O}$ in the model lumps together organic and person variables in an unspecified manner. In other ways also the model also does not divest itself of disadvantageous characteristics of radical behaviorism. For example, the model suggests that a stimulus $(\mathrm{S})$ will act on the organism $(\mathrm{O})$ to emit a behavior when certain reinforcing consequences occur. As is the case with Skinner's behaviorism (see 1975) classical conditioning and emotion are ignored. In addition, the SORC approach has the environment as a cause only once, leaving out the several roles the environment plays in the causation of behavior.

Skinner's radical behaviorism opposed theoretical analysis, including stimulus-response analysis and diagramming. In contrast PB has always demanded explicit environment-behavior analysis, and explicit analysis of biological variables, when relevant. The PB model thus states that in the analysis of beahvior there is a past learning environment $\left(\mathrm{S}_{1}\right)$ that produces through classical and operant learning principles BBRs that constitute the individual's personality. Then, later, there is the present life environment $\left(\mathrm{S}_{2}\right)$ that elicits certain elements of the repertoires that constitute the individual's behavior (B). The individual's behavior is thus a function of both the personality repertoires and the present environment, in interaction

Conceptualizing the two roles of the environment makes it possible to see that the organic state of the individual also has different roles. There is the biological state at the time the 


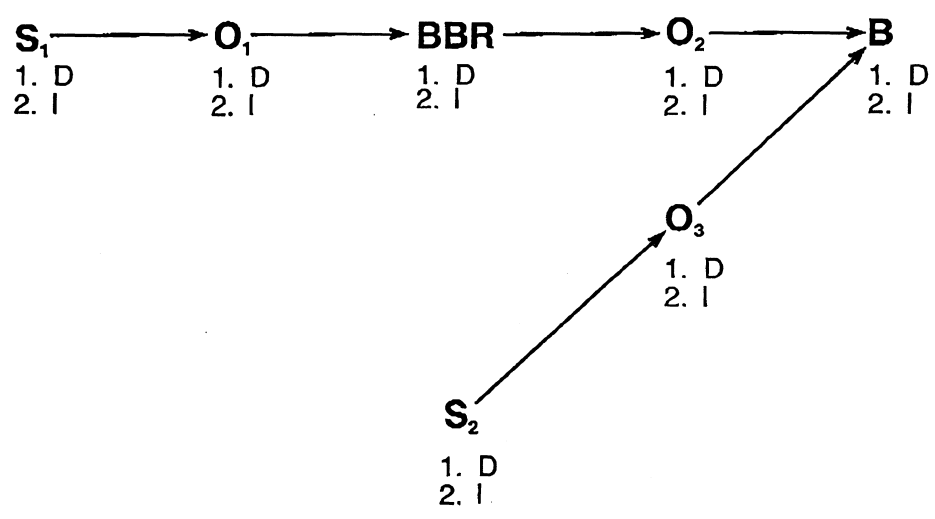

Fig. 1. The psychological behaviorism model of abnormal behavior (B). Each of the causal terms $\left(\mathrm{S}_{1}, \mathrm{O}_{1}, \mathrm{BBR}, \mathrm{O}_{2}\right.$, $\mathrm{S}_{2}$, and $\mathrm{O}_{3}$ ) can be either deficit or inappropriate, as indicated by the D and I under each term.

BBRs are being learned $\left(\mathrm{O}_{1}\right)$, there is the biological state with respect to the BBRs at the later time of behaving $\left(\mathrm{O}_{2}\right)$, and there is the biological state $\left(\mathrm{O}_{3}\right)$ with respect to the sensory apparatus and ability to perceive the current life environment. These events are depicted in Fig. 1. In PB's conception of abnormal behavior all of these events may be normal or abnormal (deficit or inappropriate). When one (or more) is abnormal the individual's behavior will be abnormal (Staats, 1975, 1996). The cause of abnormal behavior may lie in $\mathrm{S}_{1}, \mathrm{O}_{1}$, BBR, $\mathrm{O}_{2}, \mathrm{~S}_{2}$, or $\mathrm{O}_{3}$. For example, although everything has been normal for the individual, yielding normal personality repertoires, at the time of behaving the $\mathrm{O}_{2}$ condition may involve substance abuse whose biological effect may distort or delete BBRs and thus result in abnormal behavior, even in an otherwise normal life situation.

To understand, assess, and deal with the behavior disorders and other human problems it is necessary to study and stipulate the variables set forth in the model (Staats, 1996). For example, although the SORC model did not stipulate person variables, PB has studied the three repertoires that compose the BBR (personality) term, the language-cognitive, emotionalmotivational, and sensory-motor basic behavioral repertoires, that is, what they are, how they are learned, and how they function with respect to behavior. It is that specification that gives content to what is otherwise only a suggestive schematization of the "organism" term.

\section{Emotion in the functional analytic and PB approaches}

Skinner's radical behaviorism (RB) acknowledged that there is a principle of classical conditioning. But he focused on reinforcement and he ignored and downplayed classical conditioning and emotion (Skinner, 1975), as did the tradition of behavior analysis that follows his position. This deficit includes human classical conditioning and consideration of the enormous importance of emotion in human behavior. The RB position's stated methodologywhich confuses mentalism, intervening variables, and response-response mediation-has provided no basis for studying emotion and its effects (see Hayes \& Brownstein, 1986). 
This tradition, hence, could not generate the needed knowledge, and only recently has begun to employ the concept of emotion in its theoretical analyses (see Zettle \& Hayes, 1982, p. 81; Hayes, Zettle, \& Rosenfarb, 1989, pp. 207-208), although radical behaviorism has not provided a foundation for doing so. Nelson-Gray and Farmer attempt to solve the problem of this deficit in the radical behaviorism tradition by referring to Lang's (1968) triple response system, but that only describes three ways to measure anxiety; it is not a full, behavioral theory of emotion.

The lack of a theory of emotion, of individual differences in emotion, and of how emotion is involved in behavior disorders becomes apparent when the present article refers to "attitudes and beliefs" (p. 21) as though a unitary process is involved. They also say, "Recent years have witnessed a growing interest in psychotherapy approaches which primarily target emotions in order to bring about behavior change" (p. 23). However, their treatment of emotion simply accepts the concepts of traditional psychology, without analysis into explanatory behavioral terms. That is why attitudes and beliefs are not distinguished, even though they are different behavioral processes subject to different behavioral laws. Without specifying what emotions are, how they are learned, how there are individual differences in emotion, and how emotion and individual differences in emotion operate to affect behavior, the behavior therapist is given little with which to work.

That lack of development is unnecessary, however. From the beginning PB began using and developing the principles of classical conditioning in the context of understanding human behavior. How human classical conditioning takes place was studied, especially through language (Staats \& Staats, 1958; Staats, Staats, \& Crawford, 1962), and generalized to clinical (Hekmat, 1973; Hekmat \& Vanian, 1971) and educational (Staats \& Burns, 1982; Early, 1968) problems. Individual differences in emotional characteristics were investigated (Staats \& Burns, 1982; Staats, Gross, Guay, \& Carlson, 1973) and how they affect behavior. Based on such works PB has constructed a full theory of emotion (see Staats, 1963, 1975, 1996; Staats \& Eifert, 1990) and employed that conception as the basis for theories of depression (Staats \& Heiby, 1985; Heiby, 1989), the anxiety disorders (see Eifert, Evans, \& McKendrick, 1990; Plaud \& Eifert, 1998; Staats, 1972, 1975), and pain (Staats, Hekmat, \& Staats, 1996). The same behaviorism develops a theory of language (including beliefs) - how it is learned and how it functions with respect to normal and abnormal behavior. That development includes how deficits in the learned language repertoires (especially the emotioneliciting repertoire), leading to lack of social control, constitute an important part of antisocial personality disorder (see Staats 1963, pp. 384-386; 1975, p. 263).

Nelson-Gray and Farmer in various places attempt to treat traditional clinical literature. Their goal of integration is admirable but they, and behavior therapy generally, need a behaviorism that provides the tools including causative theories of emotion and language.

\section{The eclecticism of contemporary radical behaviorism unifications}

Throughout the article Nelson-Gray and Farmer employ various constructs such as "underlying psychological mechanism," "maladaptive beliefs about the self," and "negative emotions," saying that these "mechanisms are viewed as primary causal determinants of 
behavior" (p. 19). Other functional analysts and contextualists also attempt to deal with psychological concepts. But Skinner's radical behaviorism tradition, as do many behavior analysts, rejects such concepts, considering them mentalistic. This represents an inconsistency for an approach considered to derive from radical behaviorism. Moreover, that leaves the Nelson-Gray and Farmer approach without a behaviorism that provides the necessary tools and that justifies the use of such terms.

Nelson-Gray and Farmer cite the Beck position and give examples of cognitions that are employed to explain different types of PD. But there is no attempt to explain those cognitions in behavioral terms - other than suggest they involve the vague rule-governed behavior-to indicate how the cognitions are learned, and to indicate the principles involved in why those cognitions affect the individual's behavior. Lack of that analysis yields an eclectic combination, in methodology no different than that of cognitive, cognitive behavioral, and cognitive social learning approaches. Behavior therapy needs the power of explanatory analyses, and can have them by using the appropriate behaviorism.

\section{Behavioral assessment and traditional methods}

Nelson-Gray and Farmer also follow their eclecticism into the area of assessment. For example, they include a section on semi-structured interviews and self-report measures. These are methods developed in traditional psychology. The latter is justified in principle by a reference to Barrios and Hartman (1986), but these authors do not provide a behavioral analysis that indicates why self-reports can provide valuable information. Moreover, Skinner (1969, pp. 77-78) clearly rejected self reports, saying the "subject's statement of what he would do..., his estimate..., his impression..., or his evaluation" regarding his behavior or its causes are "out of the question". He states behavior can only be studied via the experimental analysis of behavior methods. Many radical-behaviorism-inspired behavior analysts retain characteristics of this position and do not accept the instruments produced in traditional psychometrics. For example, in personal exchanges on an e-mail list for behavior analysts the PB behaviorizing of the concept of intelligence and intelligence tests has been vehemently considered "verboten."

Again, there is a behaviorism that provides the necessary theoretical-empiricalmethodological bridging between behavior principles and psychometric methods and instruments (Staats, 1996). It is important to realize that the difference between eclecticism and principled theory construction is not one of esthetics. For principled theory construction is heuristic, it suggests further empirical, methodological, theoretical, and applied developments.

\section{Verbal psychotherapy and radical behaviorism derivatives}

Nelson-Gray and Farmer treat topics from abnormal psychology, assessment, and clinical treatment that includes material about verbal psychotherapy. Historically, PB first introduced a general behavioral approach to abnormal and clinical psychology (see Staats, 1963, Chap. 611). Abnormal behavior was considered to involve deficits in behavior and inappropriate 
behavior, lack of and inappropriate stimulus control of behavior, and deficit and inappropriate reinforcer systems (a taxonomy employed widely later, see Bandura, 1968; Goldfried \& Sprafkin, 1976; and pp. 25-26 of the Nelson-Gray and Farmer article). The important point here is that the $\mathrm{PB}$ position was that these various types of behavior disorders "should be accessible to change through verbal means" (Staats, 1963, p. 509) in the traditional psychotherapy situation.

But behavior modifiers in the 1960s, influenced by radical behaviorism, became fixated on the direct use of reinforcement that some of us had begun in the 1950s. Traditional psychotherapy methods were eschewed and it was necessary to break out of the radical behaviorism dogma to accept what most clinicians do-talk therapy-as a legitimate interest. so PB elaborated its earlier position in first proposing a "language behavior therapy" or "cognitive behavior therapy" (see Staats, 1972). Other behavioral psychologists contributed to opening the way to cognitive behavior therapy in the 1970s (for example, D'Zurilla \& Goldfried, 1971; Hekmat, 1973; Hekmat \& Vanian, 1971; Meichenbaum, 1977). That PB development, as it proceeded, became eclectic, accepting radical behaviorism's basic principles as well as a variety of cognitive concepts with which the principles are inconsistent.

Only in the $1980 \mathrm{~s}$, after these other developments had made talk therapy kosher did radical behaviorists also join in (Hamilton, 1988). That is a lag of 20 years, which was ineffective science for behavior therapy. And even then the functional analytic approach when it came in considered itself to have derived from radical behaviorism (see Dougher, 1993; Dougher \& Hackbert, 1994; Hayes \& Wilson, 1994; Kohlenberg \& Tsai, 1994), and to be a new and better genre. For example, Dougher (1994) rejects the concept of anxiety (as mentalistic) and cognitive therapy that attempts to reduce anxiety. Instead, Dougher says that therapy must "depotentiate disruptive contingencies" (1994, p. 49), whatever that means. So Dougher, in the pursuit of a "radical-behaviorism-sounding" approach, rejects a concept (anxiety) that has been defined behaviorially. Rather, he introduces a concept that neither derives from or has an empirical basis in behavioral principles. Let me suggest that this is representative of the functional analytic and contextualism approaches to psychotherapy. Like cognitive behavioral approaches they use a melange of inferred concepts in what represents an eclecticism that only parades as tough behaviorism.

Nelson and Farmer avoid this exuberance, but they nevertheless employ an eclectic strategy. The fact is the process of psychotherapy in its various facets can be analyzed. But that demands the use of a behaviorism that has been constructed for that purpose and that includes the necessary analytic tools, for example, a behavioral theory of language that indicates what language is (including its emotional aspects), how language is learned and can be changed through learning, as well as how language affects behavior. Skinner's Verbal behavior (1957) does not contain those needed characteristics. The vague and disputed concept of "rule governed behavior" that he later introduced did not repair these fundamental weaknesses, nor can the work on stimulus equivalence. Psychotherapy, talk therapy, is a centrally important process for changing individual behavior. The field of behavior therapy needs a behaviorism that provides a foundation for analyzing, researching, and using and advancing psychotherapy. As one example, talk therapy works less well with some behavior disorders, including antisocial personality disorder. Why constitutes an important question which only an analytic theory can address (see Staats, 1996, pp. 325-326). 


\section{Conclusion}

The Nelson-Gray and Farmer article is an important contribution to the tradition of extending a behavioral approach to understanding behavior disorders, their assessment, and treatment. This is done in a broader manner than efforts that base themselves monolithically only in radical behaviorism. But, as I have illustrated using these several topics, as an exemplar of the functional analytic tradition the paper is a model for a limited approach invested with the structure, concepts, and principles of radical behaviorisms.

Radical behaviorism is a two level theory, like all of the second-generation behaviorisms. The basic level consists of the animal behavior principles. The second level consists of the application of those principles to human behavior. That is a very simple theory approach, especially when the basic principles are simple, as has been the case when second-generation behaviorists used only simple reinforcement principles when attempting to deal with human behavior (see Dollard \& Miller, 1950; Skinner, 1953, 1957). Unfortunately, that simplicity has made radical behaviorism appealing and many behavior therapists have thought that knowing a handful of those principles is sufficient underpinning.

But human behavior is complex; the simple, two-level theory of radical behaviorism will not do the trick. Reinforcement principles are central, but emotion (and thus classical conditioning) is equally imporatnt, as well as how emotion affects behavior and how classical and operant conditioning are interrelated. So even at the basic level the theory cannot be so simple. But that is not all. While the basic principles will suffice for dealing with some behaviors, that is not the case with other behaviors. The basic principles require elaboration in the study of the learning principles that are unique to humans, as in how emotions and motor skills can be learned through language. And this level of study must consider how humans learn complex repertoires of behavior that determine their later experience, behavior, and learning. So understanding human learning and behavior demands knowing about the repertoires, not just basic principles. Moreover, a level of study must be devoted to the study of how child development involves children learning the basic behavioral repertoires in a cumulative way. Behavior therapists who intend to deal with children's problems - or with understanding the causes of adult behavior disorders-must know this material. And, with these levels in hand, it is possible to deal with a more advanced level of study, that of individual differences and personality. This, in turn, provides the basis for understanding psychometric methods and instruments in a behavioral way that is meaningful and useful for the behavior therapist. Moreover, these several levels of study then provide a richer foundation for the abnormal psychology level concerned with the analysis of the behavior disorders. Finally, the several levels of development provide a conceptual framework for the theoretical, methodological, empirical, and treatment work of the behavior therapist, including projection of new directions of advancement. (For the full approach see Staats, 1996.)

These various levels can provide a background structure of principles, methods, concepts, and findings when behavior therapists attempt to deal with topics such as those in the NelsonGray and Farmer article. I use this comment paper to indicate that behavior therapy must pay its dues. In the beginning we built the field on the basis of applying a simplification of behaviorism's basic science materials to human problems. But behavior therapy tended to accept the simple principles and that methodological position, to busy itself with applications, 
and to add on needed cognitive elaborations for psychotherapy, but without concern with systematic, unified theory construction and the power this brings. Behavior therapy has fallen away from concern with its connection to science. This is true also of cognitive-behavioral orientations since they have no real connection to cognitive science. The lack of connection has led various voices to call for theory development in behavior therapy (for example, Franks, 1998).

The behavioral tradition has much more potential power than can be achieved within a radical-behaviorism-influenced eclectic approach such as that of Nelson-Gray and Farmer. Let me suggest that it is time for behavior therapy to make a large investment in its foundations so that it can examine, use, adapt, and develop the behaviorism that is already much more advanced and also can, expeditiously, without lag, open the new avenues for widespread development that lie ahead.

\section{References}

Bandura, A. (1968). A social learning interpretation of psychological dysfunctions. In P. London, \& D. Rosenham (Ed.), Foundations of abnormal psychology. New York: Holt, Rinehart \& Winston.

Barrios, B., \& Hartmann, D. P. (1986). The contributions of traditional assessment: Concepts, issues, and methodologies. In R. O. Nelson, \& S. C. Hayes (Ed.), Conceptual foundations of behavioral assessment, (pp. 81-110). New York: Guilford.

Dollard, J., \& Miller, N. E. (1950). Personality and psychotherapy. New York: McGraw-Hill.

Dougher, M. J. (1993). On the advantages and implications of a radical behavioral treatment of private events. Behavior Therapist, 16, 204-206.

Dougher, M. J., \& Hackbert, L. (1994). A behavior-analytic account of depression and a case report using acceptance-based procedures. Behavior Analyst, 17, 321-334.

D'Zurilla, T., \& Goldfried, M. (1971). Problem solving and behavior modification. Journal of Abnormal Psychology, 78, $107-126$.

Early, J. C. (1968). Attitude learning in children. Journal of Educational Psychology, 59, 176-180.

Eifert, C. H., Evans, I. M., \& McKendrick, V. (1990). Matching treatments to client problems not diagnostic labels: A case for paradigmatic behavior therapy. Journal of Behavior Therapy and Experimental Psychiatry, 21, 245-253.

Franks, C. M. (1998). Forword. In J. J. Plaud, \& G. H. Eifert (Ed.), From behavior therapy to behavior therapy. Boston: Allyn and Bacon.

Goldfried, M., \& Sprafkin, (1976). Behavioral personality assessment. Morristown, NJ: General Learning Press.

Hamilton, S. A. (1998). Behavioral formulation of verbal behavior in psychotherapy. Clinical Psychology Review, 8, $181-194$.

Hayes, S. C., \& Brownstein, A. J. (1986). Mentalism, behavior-behavior relations, and a behavior-analytic view of the purposes of science. Behavior Analyst, 9, 175-190.

Hayes, S. C., \& Wilson, K. G. (1994). Acceptance and commitment therapy: Altering the verbal support for experiential avoidance. Behavior Analyst, 17, 289-303.

Hayes, S. C., Zettle, R. D., \& Rosenfarb, I. (1989). Rule-following. In S. C. Hayes (Ed.), Rule-governed behavior, (pp. 191-220). New York: Plenum.

Heiby, E. M. (1989). Multiple deficits in depression. Behavior Change, 6, 76-84.

Hekmat, H. (1973). Systematic versus semantic desensitization and implosive therapy: A comparative study. Journal of Consulting and Clinical Psychology, 40, 202-209.

Hekmat, H., \& Vanian, D. (1971). Behavior modification through covert semantic desensitization. Journal of Consulting and Clinical Psychology, 36, 248-251.

Iverson, G. L. (1994). Will the real behaviorism please stand up. The Behavior Therapist, 17, 191-194.

Kohlenberg, R. J., \& Tsai, M. (1994). Improving cognitive therapy for depression with functional analytic therapy: Theory and case study. Behavior Analyst, 17, 305-309.

Lang, P. J. (1968). Fear reduction and fear behavior: Problems in treating a construct. In J. M. Schtein (Ed.), Research in psychotherapy, vol. 3 (pp. 90-102). Washington, DC: American Psychological Association.

Meichenbaum, D. (1977). Cognitive-behavior modification. New York: Plenum.

Nelson-Gray, R. O., \& Farmer, R. F. (1998). Behavioral assessment of personality disorders. Behaviour Research and Therapy, , .

Plaud, J. J., \& Eifert, G. H. (1998). From behavior theory to behavior therapy. Boston: Allyn and Bacon. 
Skinner, B. F. (1953). Science and human behavior. New York: Macmillan.

Skinner, B. F. (1957). Verbal behavior. New York: Appleton-Century-Crofts.

Skinner, B. F. (1969). Contigencies of reinforcement. New York: Appleton-Century-Crofts.

Skinner, B. F. (1975). The steep and thorny way to a science of behavior. American Psychologist, 30, 42-49.

Staats, A. W. (1957). Learning theory and "opposite speech". Journal of Abnormal and Social Psychology, 55, $268-269$.

Staats, A. W. (with contributions by C. K. Staats). (1963). Complex human behavior. New York: Holt, Rinehart \& Winston.

Staats, A. W. (1972). Language behavior therapy. Behavior Therapy, 3, 165-192.

Staats, A. W. (1975). Social behaviorism. Homewood, Illinois: Dorsey Press.

Staats, A. W. (1996). Behavior and personality: Psychological behaviorism. New York: Springer.

Staats, A. W., \& Eifert, G. H. (1990). A paradigmatic behaviorism theory of emotions: A basis for unification. Clinical Psychology Review, 10, 1-40.

Staats, A. W., \& Heiby, E. M. (1985). Paradigmatic behaviorism's theory of depression. In S. Reiss, \& R. Bootzin (Ed.), Theoretical issues in behavior therapy. New York: Academic Press.

Staats, A. W., \& Staats, C. K. (1958). Attitudes established by classical conditioning. Journal of Abnormal and Social Psychology, 57, 37-40.

Staats, A. W., Staats, C. K., \& Crawford, H. L. (1962). First-order conditioning of a GSR and the parallel conditioning of meaning. Journal of General Psychology, 67, 159-167.

Staats, A. W., Gross, M. C., Guay, P. F., \& Carlson, C. C. (1973). Personality and social systems and attitude-reinforcer-discriminative theory: Attitude (interest) formation, function, and measurement. Journal of Personality and Social Psychology, 26, 251-261.

Staats, P. S., Hekmat, H., \& Staats, A. W. (1996). The psychological behaviorism theory of pain. Pain Forum, 5, $194-207$.

Zettle, R. D., \& Hayes, S. C. (1982). Rule-governed behavior: A potential theoretical framework for cognitive-behavior therapy. In P. C. Kendall (Ed.), Advances in cognitive-behavioral research and therapy (1, pp. 73-118). New York: Academic Press. 